\title{
Palliative Radiotherapy During the Last Month of Life: Have COVID-19 Recommendations Led to Reduced Utilization?
}

\author{
CARSTEN NIEDER ${ }^{1,2}$, ELLINOR C. HAUKLAND ${ }^{1,2}$, BARD MANNSAKER $^{1}$ and ROSALBA YOBUTA ${ }^{1}$ \\ ${ }^{1}$ Department of Oncology and Palliative Medicine, Nordland Hospital, Bod $\phi$, Norway; \\ ${ }^{2}$ Department of Clinical Medicine, Faculty of Health Sciences, University of Troms $\phi$, Troms $\phi$, Norway
}

\begin{abstract}
Background/Aim: The study aimed to evaluate practice changes in the time period of the early wave of the COVID-19 pandemic. Patients and Methods: This was a retrospective single institution study. We defined palliative radiotherapy (PRT) initiated before Saturday, March $14^{\text {th }}$ as pre-COVID and PRT initiated later as during-COVID (through June $\left.30^{\text {th }}\right)$. Results: National COVID-19 recommendations led to a significant decrease in PRT with 10 or more fractions, while re-irradiation and radiotherapy during the final 30 days of life were equally common before and after these recommendations had been issued in March 2020. Conclusion: Rapid adoption of modified PRT regimens was feasible. However, the challenge of overtreatment in the final phase of the disease, due to inaccurate survival prediction, persisted.
\end{abstract}

Palliative radiotherapy (PRT) is among the cornerstones of oncological approaches in patients with incurable cancer (1). In our institution, which has a dedicated PRT program that serves a small and scattered population of less than 200,000 inhabitants in rural North-Norway (large parts of Nordland County with a total of population of 243,000$)$, overtreatment and 30-day mortality (30DM) has long been a topic of research (2-6). The first comprehensive analysis related to the time period 20072009 (7). In $9 \%$ of patients, PRT was administered during the final 30 days of life. We were able to develop and validate a predictive model [presence of 6 parameters: lung or bladder cancer, Eastern Cooperative Oncology Group (ECOG) performance status (PS) of 3-4, low serum hemoglobin, opioid analgesic use, steroid use, progressive disease outside the PRT volume], which correctly identified $75 \%$ of PRT courses administered during the final 30 days of life. Given that our

This article is freely accessible online.

Correspondence to: Carsten Nieder, Department of Oncology and Palliative Medicine, Nordland Hospital, 8092 Bodø, Norway. Tel: +47 75578449, Fax: +47 75534975, e-mail: carsten.nieder@nlsh.no

Key Words: Radiotherapy, palliative treatment, prognosis, COVID-19. further research focused on PRT and survival prediction, and that only three clinical oncologists assessed patients and prescribed PRT, we hypothesized that increased awareness and knowledge about factors predicting 30DM might have led to decreased $30 \mathrm{DM}$ in a later time period. Consequently, we evaluated our data obtained between 01.09.2013 and 31.08.2014 (8). We were disappointed to learn that even in our small facility, 30DM did not improve compared to the first study (17\% in patients with metastatic cancer, $5 \%$ in those with non-metastatic cancer).

In March 2020, the global COVID-19 pandemic also arrived in Norway. On March $10^{\text {th }}$, the Norwegian Institute of Public Health had registered 277 people with confirmed infection. Based on national recommendations distributed to all oncology departments, we encouraged the utilization of altered fractionation regimens with a focus on short overall treatment time, as well as a thorough assessment of the potential benefit of PRT, as also suggested by international groups $(9,10)$. The aim of the present analysis was to evaluate the impact of COVID-19-related changes, primarily regarding PRT during the final 30 days of life and secondarily regarding PRT with 10 or more fractions.

\section{Patients and Methods}

We analyzed the treatment administered in the time period between 01.01.and 30.06.2020 and defined PRT initiated before Saturday, March $14^{\text {th }}$ as pre-COVID and PRT initiated later as during-COVID. The analysis was performed on September $13^{\text {th }}$ and survival data were available for all patients. The statistical evaluation employed the 2-tailed Fisher exact probability test (IBM SPSS v.25, significance was defined as $p \leq 0.05$ in two-sided tests).

\section{Results}

Forty-seven patients were treated in the pre-COVID phase $(0.9$ started PRT each business day; 25 received PRT for bone metastases, 53\%), including 5 re-irradiations (11\%). The largest group consisted of patients with non-small cell lung cancer $(n=15,32 \%)$. Twenty-eight patients $(60 \%)$ received 10 or more fractions. Only 3 patients $(6 \%)$, all with metastatic cancer, were treated during the final 30 days of life. 
Table I. Rate of palliative radiotherapy during the last month of life stratified by cancer types (stereotactic radiotherapy and radical treatment of oligometastases not included, all patients were older than 20 years).

\begin{tabular}{|c|c|c|c|c|c|c|}
\hline \multirow[t]{2}{*}{ Primary cancer type } & \multirow[t]{2}{*}{ Time period } & \multirow[t]{2}{*}{ Target volume } & \multirow[t]{2}{*}{ Number of fractions } & \multicolumn{3}{|c|}{ Treatment in the final } \\
\hline & & & & $2 \mathrm{wk}$ & $3 \mathrm{wk}$ & month \\
\hline \multirow[t]{2}{*}{ Prostate cancer } & Pre & 2 (prostate), 6 (oss) & $2(1), 1(8), 5(10)$ & & 1 & \\
\hline & During & 5 (oss) & $3(1), 2(5)$ & & & \\
\hline \multirow[t]{3}{*}{ Breast cancer } & Pre & 2 (oss), 2 (bra) & & & & \\
\hline & During & 4 (oss), 1 (other) & $3(10), 1(20)$ & & 1 & \\
\hline & & & $2(1), 1(5), 1(10), 1(12)$ & & & \\
\hline \multirow[t]{2}{*}{ Thyroid cancer } & Pre & 1 (oss) & $1(10)$ & & & \\
\hline & During & 1 (oss) & $1(10)$ & 1 & & \\
\hline \multirow[t]{2}{*}{ Non-small cell lung cancer } & Pre & 6 (oss), 8 (lung), 1 (bra) & 3 (2), 3 (5), 6 (10), 1 (13), 2 (15) & 1 & & \\
\hline & During & 11 (oss), 7 (lung), 3 (bra) & $4(1), 5(2), 3(5), 1(6), 2(8), 6(10)$ & & 2 & 1 \\
\hline \multirow[t]{2}{*}{ Small cell lung cancer } & Pre & 1 (bra) & $1(10)$ & & & \\
\hline & During & 2 (bra), 1 (other), 1 (lung) & $3(10), 1(15)$ & & & \\
\hline \multirow[t]{2}{*}{ Colorectal cancer } & Pre & 1 (oss), 1 (rectum), 2 (other) & $1(2), 2(5), 1(12)$ & & & \\
\hline & During & 3 (rectum), 5 (other), 1 (bra) & $2(1), 5(5), 1(7), 1(12)$ & & 1 & \\
\hline \multirow[t]{2}{*}{ Gastric cancer } & Pre & 1 (oss) & $1(5)$ & & & \\
\hline & During & & & & & \\
\hline \multirow[t]{2}{*}{ Esophageal cancer } & Pre & 1 (esophagus), 1 (oss) & $1(6), 1(13)$ & & & \\
\hline & During & 1 (esophagus), 1 (bra) & $1(10), 1(13)$ & 1 & & \\
\hline \multirow[t]{2}{*}{ Bladder cancer } & Pre & 1 (oss), 2 (other) & & & & \\
\hline & During & $1(1), 2(13)$ & & & & \\
\hline \multirow[t]{2}{*}{ Kidney cancer } & Pre & 3 (oss) & $1(7), 1(8), 1(10)$ & & & \\
\hline & During & 2 (oss), 1 (bra), 1 (other) & $1(1), 1(5), 1(10), 1(13)$ & & & \\
\hline \multirow[t]{2}{*}{ Sarcoma } & Pre & 2 (oss) & $1(9), 1(10)$ & & & \\
\hline & During & 1 (oss) & $1(5)$ & 1 & & \\
\hline \multirow[t]{2}{*}{ Hepatocellular cancer } & Pre & 1 (oss) & $1(10)$ & & & \\
\hline & During & 1 (other) & $1(13)$ & & & \\
\hline \multirow[t]{2}{*}{ Malignant melanoma } & Pre & & & & & \\
\hline & During & 2 (other), 1 (bra), 1 (oss) & $1(3), 3(5)$ & & & \\
\hline \multirow[t]{2}{*}{ Gynecological cancers } & Pre & 1 (oss) & $1(13)$ & & & \\
\hline & During & 1 (other) & $1(10)$ & & & \\
\hline \multirow[t]{2}{*}{ Pancreatic cancer } & Pre & 1 (pancreas) & $1(12)$ & & & \\
\hline & During & & & & & \\
\hline \multirow[t]{2}{*}{ Multiple myeloma } & Pre & 3 & $1(5), 1(6), 1(10)$ & & & \\
\hline & During & 5 & $1(4), 4(5)$ & & & \\
\hline \multirow[t]{2}{*}{ Lymphoma } & Pre & & & & & \\
\hline & During & 3 & $1(5), 1(8), 1(10)$ & 1 & & \\
\hline \multirow[t]{2}{*}{ Others } & Pre & & & & & \\
\hline & During & 1 (other), 1 (lung) & $1(5), 1(10)$ & & & \\
\hline
\end{tabular}

oss: Bone metastases; bra: brain metastases; other: lymph nodes and soft tissue.

Seventy-one patients were treated in the during-COVID phase (1.0 started PRT each business day; 29 received PRT for bone metastases, $41 \%$ ), including 7 re-irradiations (10\%). The largest group consisted of patients with non-small cell lung cancer $(\mathrm{n}=21,30 \%)$. Twenty-four patients $(34 \%)$ received 10 or more fractions. Eight patients $(11 \%$; 7 with metastatic cancer and 1 with lymphoma) were treated during the final 30 days of life (Table I).

For both time periods combined, i.e. the first half of 2020 , 9\% of all patients received PRT during the final 30 days of life. Non-small cell lung cancer was a common diagnosis in these patients. None of the deaths was related to COVID-19.
The only statistically significant difference regarding the data reported in the Results section relates to a reduced utilization of PRT with 10 or more fractions ( $p=0.008$, 2-tailed Fisher exact probability test).

\section{Discussion}

The COVID-related fractionation recommendations issued in March 2020 resulted in a significant change in PRT fractionation in this single-institution study. In contrast, the number of new patients who started PRT each business day, reirradiation utilization, and the number of patients who received 
PRT during the final 30 days of life remained stable. Overall, $9 \%$ of all patients who received PRT did so during the final 30 days of life in the first 6 months of 2020. In our first analysis (2007-2009), an identical rate of $9 \%$ was reported (7). A recent study from Australia found that deaths within 14 and 30 days of treatment with radiotherapy were 3.8 and $8.0 \%$, respectively (11). Wu et al. analyzed 518 patients treated with external beam radiotherapy to a site of metastatic disease between 2012 and 2016 (12). Median time from radiotherapy to death was 74 days. One hundred and twenty-five patients (24\%) died within 30 days of irradiation. A systematic review by Park et al. found PRT utilization rates during the last month of life in the range of 5-10\% among patients who died of cancer, and in $9-15 \%$ of patients who received PRT (13). The most commonly used regimen was $30 \mathrm{~Gy}$ in 10 fractions (36-90\%). Single fraction RT utilization ranged from $0 \%$ to $59 \%$. ECOG PS 3-4 was significantly associated with patients receiving RT in the last 30 days of life and a shorter survival. In line with our current results, previous experience (14) also suggested that PRT utilization during the final 30 days of life has remained relatively stable over time, despite the publication of predictive models that aimed at the identification of patients with a very short survival $(15,16)$.

It would be interesting to compare our results with those obtained in other regions of the world, especially regions where the pandemic has had a greater impact on the healthcare system and death rates $(17,18)$. Our healthcare region (Nordland county) with 243,000 inhabitants (some served by other hospitals) has seen a relatively low number of people with COVID-19 infections (110 cases until August $31^{\text {th }}$, no reported death due to the infection, sufficient intensive care resources to handle all hospitalized patients). Consequently, oncology care has largely continued as planned (under certain precautions such as procedures for testing and quarantine). Other regions might have seen lower rates of PRT during the final 30 days of life than under pre-COVID operations, if patient selection and prioritization was changed. However, higher rates might also occur if patients who otherwise would have survived have died from COVID-19. It will also be interesting to learn whether the observed change in PRT fractionation simply reflects a desirable development (19-21), accelerated by the pandemic, or if some patients experience harm due to undertreatment.

\section{Conflicts of Interest}

The Authors declare that they have no conflicts of interest in relation to this study.

\section{Authors' Contributions}

$\mathrm{CN}, \mathrm{BM}$ and RY collected and analyzed the patient data. $\mathrm{CN}$ and $\mathrm{EH}$ drafted the manuscript. All Authors read and approved the final manuscript.

\section{References}

1 Nieder C, Pawinski A, Haukland E, Dokmo R, Phillipi I and Dalhaug A: Estimating need for palliative external beam radiotherapy in adult cancer patients. Int J Radiat Oncol Biol Phys 76(1): 207-211, 2010. PMID: 19362788. DOI: 10.1016/ j.ijrobp.2009.01.028

2 Nieder C, Yobuta R, Mannsåker B and Dalhaug A: How should palliative thoracic radiotherapy be fractionated for octogenarians with lung cancer? In Vivo 32(2): 331-336, 2018. PMID: 29475917. DOI: 10.21873 /invivo. 11242

3 Nieder C, Mannsåker B, Dalhaug A, Pawinski A and Haukland E: Palliative radiotherapy in cancer patients with increased serum C-reactive protein level. In Vivo 30(5): 581-586, 2016. PMID: 27566075.

4 Nieder C, Dalhaug A, Haukland E and Engljähringer K: Patientreported symptom burden, rate of completion of palliative radiotherapy and 30-day mortality in two groups of cancer patients managed with or without additional care by a multidisciplinary palliative care team. Anticancer Res 38(4): 2271-2275, 2018. PMID: 29599349. DOI: 10.21873/anticanres.12471

5 Nieder C, Norum J, Hintz M and Grosu AL: Short survival time after palliative whole brain radiotherapy: Can we predict potential overtreatment by use of a nomogram? J Cancer $8(9)$ : 1525-1529, 2017. PMID: 28775771. DOI: 10.7150/jca.18600

6 Nieder C, Tollåli T, Dalhaug A, Haukland E, Aandahl G, Pawinski A and Norum J: Active anticancer treatment during the final month of life in patients with non- small cell lung cancer. Anticancer Res 34(2): 1015-1020, 2014. PMID: 24511048.

7 Angelo K, Norum J, Dalhaug A, Pawinski A, Aandahl G, Haukland E, Engljähringer K and Nieder C: Development and validation of a model predicting short survival (death within 30 days) after palliative radiotherapy. Anticancer Res 34(2): 877885, 2014. PMID: 24511026.

8 Nieder C: Palliative radiotherapy (PRT) during the last month of life: A constant sorrow even in a dedicated PRT facility with research focus on this endpoint. Radiother Oncol 115(2): 284, 2015. PMID: 25981051. DOI: 10.1016/j.radonc. 2015.04.0173

9 Guckenberger M, Belka C, Bezjak A, Bradley J, Daly ME, DeRuysscher D, Dziadziuszko R, Faivre-Finn C, Flentje M, Gore E, Higgins KA, Iyengar P, Kavanagh BD, Kumar S, Le Pechoux C, Lievens Y, Lindberg K, McDonald F, Ramella S, Rengan R, Ricardi U, Rimner A, Rodrigues GB, Schild SE, Senan S, Simone CB 2nd, Slotman BJ, Stuschke M, Videtic G, Widder J, Yom SS and Palma D: Practice recommendations for lung cancer radiotherapy during the COVID-19 pandemic: An ESTRO-ASTRO consensus statement. Int J Radiat Oncol Biol Phys 107(4): 631-640, 2020. PMID: 32589990. DOI: 10.1016/ j.ijrobp.2020.05.012

10 Achard V, Aebersold DM, Allal AS, Andratschke N, Baumert BG, Beer KT, Betz M, Breuneval T, Bodis S, de Bari B, Förster R, Franzetti-Pellanda A, Guckenberger M, Herrmann E, Huck C, Khanfir K, Matzinger O, Peguret N, Pesce G, Putora PM, Reuter C, Richetti A, Vees H, Vrieling C, Zaugg K, Zimmermann F, Zwahlen DR, Tsoutsou P and Zilli T: A national survey on radiation oncology patterns of practice in Switzerland during the COVID-19 pandemic: Present changes and future perspectives. Radiother Oncol 150: 1-3, 2020. PMID: 32512075. DOI: 10.1016/j.radonc.2020.05.047 
11 Pitson G, Matheson L, Garrard B, Eastman P and Rogers M: Population-based analysis of radiotherapy and chemotherapy treatment in the last month of life within regional Australia. Intern Med J 50(5): 596-602, 2020. PMID: 31161700. DOI: 10.1111/imj.14377

$12 \mathrm{Wu}$ SY, Singer L, Boreta L, Garcia MA, Fogh SE and Braunstein SE: Palliative radiotherapy near the end of life. BMC Palliat Care 18(1): 29, 2019. PMID: 30904024. DOI: 10.1186/s12904-019-0415-8

13 Park KR, Lee CG, Tseng YD, Liao JJ, Reddy S, Bruera E and Yennurajalingam S: Palliative radiation therapy in the last 30 days of life: A systematic review. Radiother Oncol 125(2): 193-199, 2017. PMID: 29050955. DOI: 10.1016/j.radonc.2017.09.016

14 Spencer K, Morris E, Dugdale E, Newsham A, SebagMontefiore D, Turner R, Hall G and Crellin A: 30 day mortality in adult palliative radiotherapy - A retrospective population based study of 14,972 treatment episodes. Radiother Oncol 115(2): 264-271, 2015. PMID: 25861831. DOI: 10.1016/ j.radonc.2015.03.023

15 Nieder C, Marienhagen K, Dalhaug A, Aandahl G, Haukland E and Pawinski A: Prognostic models predicting survival of patients with brain metastases: integration of lactate dehydrogenase, albumin and extracranial organ involvement. Clin Oncol (R Coll Radiol) 26(8): 447-452, 2014. PMID: 24702741. DOI: $10.1016 /$ j.clon.2014.03.006

16 Nieder C, Marienhagen K, Thamm R, Astner ST, Molls M and Norum J: Prediction of very short survival in patients with brain metastases from breast cancer. Clin Oncol (R Coll Radiol) 20(5): 337-339, 2008. PMID: 18423991. DOI: 10.1016/j.clon.2008. 03.005
17 Gonnelli A, Montrone S, Cocuzza P, Ursino S, Manfredi B, Mattioni R, Coccia N, Fuentes T, Calistri E, Pasqualetti F and Paiar F: Radiotherapy in the COVID-19 pandemic era. In Vivo 34(6): 3731-3734, 2020. PMID: 33144491. DOI: 10.21873/invivo.12222

18 Wang W, Liu X, Zhang F, Qiu J and Hu KE: Radiation therapy during the COVID-19 pandemic: Experience from Beijing, China. In Vivo 34(3 Suppl): 1675-1680, 2020. PMID: 32503828. DOI: 10.21873 /invivo.11960

19 Chow R, Hoskin P, Schild SE, Raman S, Im J, Zhang D, Chan S, Chiu N, Chiu L, Lam H, Chow E and Lock M: Single vs multiple fraction palliative radiation therapy for bone metastases: Cumulative meta-analysis. Radiother Oncol 141: 56-61, 2019. PMID: 31445837. DOI: 10.1016/j.radonc.2019.06.037

20 Nieder C, Pawinski A and Dalhaug A: Continuous controversy about radiation oncologists' choice of treatment regimens for bone metastases: should we blame doctors, cancer-related features, or design of previous clinical studies? Radiat Oncol 8: 85, 2013. PMID: 23574944. DOI: 10.1186/1748-717X-8-85

21 Nieder C, Dalhaug A, Haukland E, Mannsåker B and Pawinski A: Contemporary radiooncological management of bone metastases from breast cancer: factors associated with prescription of different fractionation regimens (short or long course) in a rural part of North Norway with long travel distance. Int J Circumpolar Health 76(1): 1270080, 2017. PMID: 28452680. DOI: 10.1080/22423982.2016.1270080

Received November 14, 2020

Revised December 4, 2020

Accepted December 5, 2020 